\title{
A PARTICIPAÇÃO SOCIAL DOS AGRICULTORES FAMILIARES DE ALFREDO MARCONDES/SP NA IMPLANTAÇÃO DO PRONAF/INFRAESTRUTURA: GESTÃO COMPARTILHADA, CIDADANIA E EDUCAÇÃO
}

Aparecida José Martines de Oliveira ${ }^{1}$, José Camilo dos Santos Filho ${ }^{2}$

${ }^{1}$ Discente do Mestrado em Educação da UNOESTE, ${ }^{2}$ Docente do Mestrado em Educação da UNOESTE. E-mail: jcamilosantos@yahoo.com.br

\section{RESUMO}

O presente artigo faz parte da pesquisa documental que integra o projeto de pesquisa do mestrado em educação da UNOESTE, (cadastro na CCPq no 1635) e objetiva investigar como se deu o processo participativo dos agricultores familiares de Alfredo Marcondes na implantação do Programa Nacional de Fortalecimento da Agricultura familiar.

Trata-se de reconstruir e analisar a experiência formativa dos agricultores familiares no seu contexto processual e metodológico, para compreender o modelo adotado para a elaboração do Plano Municipal de Desenvolvimento Rural - PMDR de forma participativa.

Palavras-chave: participação social, níveis de participação; gestão compartilhada; cidadania; educação.

\section{INTRODUÇÃO E OBJETIVO}

O processo de gestão do PRONAF/infraestrutura nesse município teve inicio a partir do ano de 1996, quando foi selecionado pelo Ministério da Agricultura - MA juntamente com outros dois municípios da região do Pontal do Paranapanema (SP), para receberem o aporte de recursos financeiros do Orçamento Geral da União, conforme critérios pré-estabelecidos por esse Programa.

Contudo, para habilitar-se ao credenciamento dos repasses do PRONAF/ Infraestrutura, o MA, condicionou-o à apresentação do PMDR, compreendido para o período de 1997 a 2000 que deveria ser elaborado com a participação dos agricultores familiares.

Visando a obtenção dos dados que pudessem retratar a realidade do meio rural desse município e possibilitar a participação da maioria os agricultores familiares no diagnóstico e na elaboração do PMDR, o engenheiro agrônomo - Diretor do Departamento Municipal de Agricultura fez uso da metodologia "Ziel Orientirte Projekt Planung - ZOOP" que de acordo com Bergamasco et al. $(1996$, p. 7) "a tradução mais apropriada parece ser planejamento de projetos orientados para objetivos".

Considerando o exposto este estudo busca compreender a estratégia dos técnicos da Prefeitura Municipal e Coordenadoria de Assistência Técnica Integral - CATI para informar, 
mobilizar e envolver os agricultores familiares na elaboração de uma proposta de desenvolvimento rural, a partir das prioridades e pleitos formulados pelos próprios agricultores observando-se os ganhos em termos de aprendizagens, organização política e construção de saberes para o exercício da cidadania e tem por objetivo:

- Identificar os níveis de participação social dos agricultores familiares no planejamento e implantação do PRONAF/Infraestrutura;

- Destacar os aspectos gestionários e educativos ocorridos durante a elaboração do plano municipal de desenvolvimento rural.

\section{METODOLOGIA}

O presente estudo envolve pesquisa documental (fonte primária) realizada nos arquivos da APRAM, do CMDR e da Prefeitura Municipal de Alfredo Marcondes (SP).

Segundo Cellard (2008, p. 295),

[...] o documento escrito constitui uma fonte extremamente preciosa para todo pesquisador nas ciências sociais. Ele é, evidentemente, insubstituível em qualquer reconstituição referente a um passado relativamente distante, pois não é raro que ele represente a quase totalidade dos vestígios da atividade humana em determinadas épocas. Além disso, muito frequentemente, ele permanece como o único testemunho de atividades particulares ocorridas num passado recente.

Conforme esse autor, a análise documental contribui com a observação do processo de amadurecimento e evolução de indivíduos, grupos, conceitos, conhecimentos, comportamentos, mentalidades, práticas dentre outros.

É importante também ressaltar que a própria autora mantém um envolvimento com a problemática estudada, acumulando não apenas a experiência do movimento enquanto ele acontecia, mas também registrando os acontecimentos através de relatórios e cadernos de campo conforme a dinâmica do movimento.

\section{RESULTADOS}

Conforme documentos pesquisados junto à APRAM e ao CMDR a iniciação à participação dos agricultores familiares na elaboração do PMDR foi formulada, através de consulta efetuada por meio de questionário elaborado pelo agrônomo responsável pela Casa de Agricultura e Diretor do Departamento Municipal de Agricultura, que foi entregue a 228 produtores familiares (100\%) 
que aquela época se adequava neste perfil, conforme critério de conceituação e caracterização do MA/CATI/PRONAF.

Em sua primeira parte, o questionário continha, nota explicativa que informava qual era o seu objetivo e foi composto de seis questões abertas que após a devolução, foram analisadas pelo CMDR, pela APRAM, pelo Sindicato dos Trabalhadores Rurais e demais representantes que os próprios produtores familiares indicaram para a consecução do fim proposto. O questionário constituía-se das seguintes questões:

SENHOR Produtor:

O Governo Federal deseja fortalecer a Agricultura Familiar, e disse que tem alguns recursos a fundo perdido para aplicar em nosso Município, porém precisamos fazer um Plano de Desenvolvimento Rural do Município com a participação dos produtores Familiares, com o objetivo de decidir o que nos interessa para o desenvolvimento do nosso setor rural. Assim, solicitamos pôr gentileza que nos responda o questionário abaixo e nos entregue devidamente preenchido até o dia 3 de dezembro de 1996.

Lembre-se, sua colaboração é decisiva e muito importante. Obrigado.

1- Você quer participar do grupo que vai colaborar para fazer este plano?

2- Qual a pessoa do seu Bairro ou Cidade que você indicaria para representa-lo junto a uma entidade?

3 - Qual a sua principal atividade agropecuária?

4- Quais os principais problemas enfrentados na atividade agropecuária do nosso Município?

5- Você sugere outro tipo de atividade para ser explorada em nosso município? Qual? Porque?

6- O que você acha que é preciso fazer para desenvolver o setor rural do nosso município?

A seguir, descreve-se a consolidação dos dados obtidos através do questionário.

Tabela 1. Demonstrativo da adesão ao questionário aplicado.

\begin{tabular}{|l|l|l|}
\hline Questionários & No & $\%$ \\
\hline Não devolvidos & 143 & 62,72 \\
\hline Devolvidos preenchidos & 80 & 35,09 \\
\hline Devolvidos em branco & 05 & 2,19 \\
\hline Total (distribuídos) & $\mathbf{2 2 8}$ & $\mathbf{1 0 0 , 0 0}$ \\
\hline
\end{tabular}

Fonte: Tabela 53 do PMDR 1997-2000 do município de Alfredo Marcondes, p.42. 
Tabela 2. Demonstrativo do total dos 80 questionários respondidos pelos agricultores familiares quanto a disponibilidade de participarem da elaboração do PMDR.

\begin{tabular}{|l|l|l|}
\hline Deseja participar da elaboração do PMDR & No & $\mathbf{\%}$ \\
\hline Sim & 63 & 78,75 \\
\hline Não & 13 & 16,25 \\
\hline Não respondeu & 04 & 5,00 \\
\hline Total & $\mathbf{8 0}$ & $\mathbf{1 0 0 , 0 0}$ \\
\hline
\end{tabular}

Fonte: Tabela 54 do PMDR 1997-2000 do município de Alfredo Marcondes, p.42.

Tabela 3. Demonstrativo da justificativa dos pesquisados que responderam que não desejariam participar da elaboração do PMDR.

Justificativa

Não quero participar deste plano de desenvolvimento rural, pois só ouvimos conversa fiada e nada acontece.

Não quero participar por que:

- Acho que o produtor rural esta cansado de ouvir conversa fiada e esta abandonando as suas propriedades e arrumando serviço na cidade.

- É preferível ficar parado a arriscar perder parte do patrimônio adquirido.

Não justificaram

Total

Fonte: Tabela 55 do PMDR 1997-2000 do município de Alfredo Marcondes, p.42.

\begin{tabular}{|l|l|}
\hline № & $\%$ \\
\hline 02 & 15 \\
\hline
\end{tabular}

$02 \quad 15$

0970

13100,00

A partir das informações obtidas com a aplicação do questionário os técnicos do Departamento Municipal de Agricultura responsável pela implantação desse programa, tabularam as informações, que foram agrupadas da seguinte forma: os problemas, as causas, aspirações e soluções para o desenvolvimento rural. Estes itens foram objeto de discussão das (questões 4, 5 e 6) valendo destacar, que todos os problemas, potencial, causas e alternativas para viabilizar a agricultura familiar foram debatidos exaustivamente na plenária da Assembleia realizada no dia 02 de maio de 1997 com os diversos representantes indicados pelos agricultores familiares, poder público local, Secretaria de Agricultura e Abastecimento do Estado de São Paulo/CATI, Sindicato dos Trabalhadores Rurais, APRAM e CMDR de Alfredo Marcondes.

\section{DISCUSSÃO}

O questionário aplicado, apesar de ter sido respondido por apenas $(35,09 \%$ dos agricultores familiares) permitiu iniciar um processo dialógico gerando os dados necessários para retratar o contexto sócio econômico dos agricultores familiares e o potencial das Unidades de Produção Familiar - UPF's do Município. 
Nos documentos pesquisados nos arquivos da APRAM encontra-se a memória deste movimento que nos permite historiar os fatos a partir dos avanços e obstáculos que foram se manifestando ao longo da implantação do Programa no período de 1996-1997.

Conforme relato colhido em abril/2013 do Engenheiro Agrônomo Joel Martines de Oliveira responsável pela aplicação da metodologia buscou-se, também,

Estabelecer um diálogo; ouvir através da consulta por meio do questionário para que, com a participação dos interessados, pudesse melhor planejar estes investimentos a partir das necessidades, das demandas, dos sonhos, das esperanças, das aspirações e também as desesperanças e conflitos que marcam as vidas destes produtores familiares. Por isso ele assumiu seu papel enquanto técnico e facilitador da metodologia participativa disponibilizada pela CATI, porque quem ama assume riscos e se compromete com as causas daqueles a quem defende.

É precisamente isso que Freire (1991, p.45), nos ensina,

O amor é compromisso com os homens. Onde quer que estejam estes, oprimidos, o ato de amor está em comprometer-se com sua causa. A causa da sua libertação. Mas, este compromisso, porque é amoroso, é dialógico. Como ato de valentia, não pode ser piegas; como ato de liberdade, não pode ser pretexto para a manipulação... A não ser assim, não é amor... Se não amo o mundo, se não amo a vida, se não amo os homens, não me é possível o diálogo.

Apesar do empenho do Técnico Departamento Municipal de Agricultura em entregar e explicar pessoalmente o objetivo da referida pesquisa, $(62,72 \%)$ dos produtores familiares não devolveram o questionário e apenas, (35,09\%) devolveram o mesmo preenchido.

Dos 80 agricultores que responderam o questionário apenas $(78,75 \%)$ demonstrou interesse em participar da elaboração do PMDR, enquanto que, (16,25\%) disseram que não desejaria e (5\%) não responderam a essa questão.

Dos 13 agricultores familiares que responderam que não desejariam participar, (15\%) justificaram da seguinte forma "Eu não quero participar deste plano de desenvolvimento Rural, pois só ouvimos conversa fiada e nada acontece"; Fica evidenciada no descontentamento manifestado a ausência de respostas ou morosidade do poder público (municipal, estadual e federal) às demandas apresentas por esse segmento. E ainda, (15\%) dos pesquisados se remete à questão das dificuldades de permanecer nessa atividade econômica, conforme citado na seguinte linguagem: "Eu acho que o produtor rural esta cansado de ouvir conversa fiada e estão 
abandonando as suas propriedades e arrumando serviço na cidade". Ou ainda, fica demonstrada na frase: "É preferível ficar parado a arriscar perder parte do patrimônio adquirido".

Estes dados explicitam os motivos da indiferença de (63\%) dos agricultores familiares que não devolveram o questionário e de (22\%) que responderam ao questionário dizendo não queriam participar da elaboração do PMDR, o que denota a falta de esperança desse segmento e a desmotivação em participar de uma proposta voltada para a resolução dos problemas individuais e coletivos que afetam diretamente o cotidiano do agricultor familiar.

O quadro acima é conceituado por Modesto como - as três situações patológicas da participação política, á saber: a apatia; a abulia e a acracia.

Segundo esse autor a apatia política,

(...) relaciona-se mais diretamente à falta de informação sobre os direitos e deveres dos cidadãos; a falta de vias de comunicação direta realmente ágeis do cidadão em face do aparato do Estado; a falta de resposta a solicitações; a falta de tradição participativa e à excessiva demora na resposta de solicitações ou críticas.

A abulia política (não querer participar da ação cidadã),

(...) relaciona-se, por sua vez, com o ceticismo quanto a manifestação do cidadão efetivamente ser levada em consideração pela administração pública, bem como pela falta de reconhecimento e estima coletiva para atividades de participação cidadã.

Enquanto que, a acracia política (não poder participar da ação cidadã),

(...) relaciona-se à complexidade e prolixidade excessiva das normas administrativas, além dos graves problemas de ordem política e econômica própria de países subdesenvolvidos.

Para o presente estudo de caso, observa-se que as causas dessa desmotivação estão diretamente relacionadas às questões de ordem política e econômica que advêm das tentativas frustradas dos produtores familiares em permanecerem na atividade em razão da ausência de uma política agrícola nacional especificamente voltada para esse importante setor da economia que produz os alimentos básicos que sustentam a vida.

As informações contidas em cada pergunta do referido questionário foram devidamente consolidadas, tabuladas e transcritas em tarjetas, explicitando os problemas, causas, potencial e aspirações, que resultaram no diagnóstico, que possibilitou aos representantes decidir e encaminhar em assembleia geral dos agricultores familiares realizadas no meses de abril e 
maio/1997 as prioridades sugeridas como alternativas de intervenção na zona rural do município objetivando a reversão da situação sócio-econômico-ambiental desse setor.

A efetivação dos recursos financeiros do PRONAF/ Infraestrutura e Serviços Municipais ocorreram em Alfredo Marcondes (SP) permeado primeiramente pela desconfiança dos pequenos produtores que participavam da elaboração do PMDR de que os investimentos realmente chegariam à ponta. Muitas eram as dúvidas, mas a principal era: ser ano de eleições nas três esferas de governo. A mudança de governos principalmente da esfera federal e municipal poderia paralisar ou até mesmo extinguir o referido programa? Assim transcorreu o ambiente de negociações, alguns apoiando e acreditando na proposta, enquanto outros, desestimulados não queriam participar.

No transcorrer da tabulação dos dados do questionário e da realização da Assembleia para definição dos pleitos, as sugestões dos técnicos da CATI representada nesta região pelo Escritório de Desenvolvimento Rural de Presidente Prudente, era no sentido de que o investimento do PRONAF devesse priorizar a instalação de agroindústria no Município. A esta sugestão, contestaram os agricultores indicados para elaborar o PMDR. Diziam que a demanda principal indicada no questionário pela maioria dos produtores familiares (12\%) apontava a aquisição de uma patrulha agrícola com o fim de oferecer uma infraestrutura de produção de utilização coletiva. Esta era uma das intervenções possíveis de ser efetivada com estes recursos. As demais reivindicações eram: financiamentos subsidiados, preços mínimos, taxas de juros elevadas, seguro agrícola com cobertura total eram da alçada do governo federal e dependiam, portanto, uma política agrícola nacional exclusivamente voltada para a agricultura familiar. Para tanto, a forma de incidir sobre esta política se faria segundo os produtores familiares pressionando os deputados estaduais e federais da região e a bancada paulista na Câmara Federal.

Na definição da política agrícola municipal a ser implementada com estes recursos do PRONAF/Infraestrutura diziam eles, em relatos de reuniões datadas de abril de 1997:

Temos que priorizar uma tecnologia mínima que permita conservar o solo, preparar a terra, fazer o plantio e a nossa colheita. Do que adianta instalar agroindústria se não tiver matéria prima suficiente e com oferta constante para ser processada? Se, os investimentos dos quatro anos do PRONAF forem suficientes para investir em motomecanização agrícola e na verticalização da produção (através de instalação de uma agroindústria) assim será feito, caso contrário fica priorizado em primeiro lugar a aquisição de tratores e implementos agrícolas em quantidade suficientes para atender exclusivamente a demanda dos produtores familiares. 
Por outro lado, alguns técnicos da CATI tomando por parâmetro a experiência de alguns municípios vizinhos, cujas prefeituras haviam disponibilizado tratores e implementos agrícolas para os pequenos agricultores, argumentavam que estes equipamentos em menos de dois anos estariam sucatados e que, portanto, investir em patrulha agrícola não era a melhor opção. No entanto, os produtores familiares permaneceram firmes em seus propósitos indicando no PMDR os pleitos que entendiam satisfazer realmente às suas demandas.

É importante ressaltar o ambiente de companheirismo e de respeito mútuo, permeado pelo comportamento ético, transparência e lisura em que ocorreu a realização deste processo participativo. Os diálogos respeitosos, abertos e francos entre os técnicos da Prefeitura Municipal e da CATI com agricultores familiares marcaram o encaminhamento da seleção dos pleitos, determinando os programas e projetos que deveriam integrar o Plano Municipal de Desenvolvimento Rural - PMDR 1997-2000.

Na dinâmica estabelecida para a elaboração do PMDR foi possível os agricultores familiares em parceria com os técnicos formatar uma proposta de gestão compartilhada dos equipamentos adquiridos com recursos do PRONAF/infraestrutura. Os membros do CMDR eleitos em assembleia geral pelos agricultores familiares no dia 30/04/1997 estabeleceram os critérios por meio de resolução do CMDR autorizando a Associação dos Produtores Rurais - APRAM a gerenciar esses equipamentos que seriam cedidos pela Prefeitura Municipal mediante cessão de uso em comodato. Essa gestão compartilhada do PRONAF/infraestrutura foi posteriormente aprovada pela Lei Municipal 2201/1998 tornando-se uma política de Estado em âmbito municipal.

\section{CONCLUSÃO}

Esse estudo de caso constatou que há vários níveis de participação social, mas que nem todo processo participativo tem o mesmo alcance. Que para compreender melhor as ações de intervenção dos indivíduos e grupos, é necessário examinar os níveis em que se desenvolvem. Pode-se distingui-los da seguinte forma:

- A Informação e a consulta que ocorreu com a mobilização dos agricultores familiares através do questionário e sua respectiva nota explicativa condicionava ao recebimento dos recursos destinados pelo PRONAF/Infraestrutura - elaboração do PMDR/1997-2000 que deveria priorizar os pleitos em que os recursos financeiros desse programa deveriam ser investidos. Essa opinião se constituiu em um elemento de juízo para a tomada de decisões. 
- À medida que os agricultores familiares participavam das decisões tiveram a iniciativa de formular as sugestões destinadas a mitigar ou a resolver problema que lhes são comuns e que isoladamente não teriam condições financeiras de investir. A forma de organização social desse grupo demonstra que a participação política é a base constitutiva da cidadania e que a gestão compartilhada contribui para a formação da consciência de direitos e obrigações, que são os instrumentos básicos que permitem aos agricultores familiares participarem do poder, assegurando a continuidade da política municipal de agricultura independentemente de quem ocupe o poder na esfera municipal.

\section{REFERÊNCIAS}

Associação dos Produtores Rurais de Alfredo Marcondes - APRAM (SP). Estatuto Social. Alfredo Marcondes: Arquivo da APRAM, 1990.

CELLARD, A. A análise documental. In: POUPART, J. et al. A pesquisa qualitativa: enfoques epistemológicos e metodológicos. Petrópolis, Vozes, 2008.

. Decreto no 1.946, de 28 de junho de 1996. Cria o Programa Nacional de Fortalecimento da Agricultura Familiar - PRONAF, e dá outras providências.

FREIRE, Paulo. Pedagogia do oprimido. 17ạ ed. Rio de Janeiro: Paz e Terra, 1987.

MODESTO, Paulo. Participação popular na administração pública. Mecanismos de operacionalização. Jus Navigandi, Teresina, ano 6, n. 54, fev. 2002. Disponível em: http://jus2.uol.com.br/doutrina/texto. Acesso em: 22/jul/ 2006.

OLIVEIRA, Aparecida J. Martines de \& JÚNIOR, Nabor F. da Silva. Evolução Histórica e Aspectos do Meio Rural do Município de Alfredo Marcondes. Presidente Prudente: UNESP/FCT 1.996, p.27.

Plano Municipal de Alfredo Marcondes - PMDR 1997-2000. Prefeitura Municipal, 1997. 